\title{
Reasons of Dropouts and Defaulters of Medical Students in Bangladesh
}

\author{
Dr. Md. Abdal Miah', Dr. Md Abdul Wohab Khan'², Dr. Md. Humayun Kabir Talukder ${ }^{3}$,Dr. Ferdousi Begum ${ }^{4}$, \\ Dr. Tahmina Nargis ${ }^{5}$, Dr. Tabassum Ferdous Khan ${ }^{6}$, Dr. Rawshan AraKhanam ${ }^{7}$, Dr. Golam Rabbi ${ }^{8}$, \\ Dr. TauhidurRahman", Dr. Wakil Ahmed ${ }^{10}$, Prof. Dr S M Idris Ali ${ }^{l 1}$.
}

\begin{abstract}
This descriptive type of cross sectional study was carried out to find out the causes of dropouts and repeated failures (defaulters) of medical students in Bangladesh. The study was carried out in seven (Three government and four Nongovernment) medical colleges in Bangladesh over a period from July 2011 to June 2012. All dropout and defaulter students were the study population. A total of 59 respondents were interviewed, out of them 11 respondents were dropouts and 48 were defaulters. Convenience sampling technique was adopted and data was collected by the researcher himself.

Data was collected from those who got admitted in medical college in the year 2003 and thereafter. So, medial students of different level and intern doctors, who were agreed, were enrolled for collection of data by face to face in depth interview.

Study revealed that the most important reasons for dropouts and defaulters were lacking of personal interest and less capability for understanding the medical subjects, non-friendly and non-cooperative attitude of teachers; content overloaded curriculum and threatening environment of oral examinations; personal illness and illness of family members; poor institutional set up; lack of facilities for counseling and remedial actions. Among the respondents it was also found that the male and the higher economic class students were more dropped out or became defaulters in the professional examinations.

Study also revealed some valuable suggestions to avoid occurrences of dropouts and defaulters. Suggestions were strict regularity, sincerity and attention should be paid to all types of classes including lectures, clinical, tutorial and practical; personal interest and ability should be given highest importance in case of medical admission. They also emphasized on the revision of medical curriculum where the needs of the students would be reflected and the curriculum should be more appropriate and practical oriented. A coordinated class, tutorials and examination system should be developed in each medical college, so that all students can prepare themselves for examination properly. They also suggested that teachers and examiners at all levels should be friendly and cooperative, and should pay special attention to the poor performing students to overcome their weaknesses. They also suggested that study in partnership should be encouraged and there should be adequate hostel arrangement with proper food and recreation facilities. The respondents also suggested for provision of counseling facilities and make-up classes for academically weak students. They further suggested that special sympathy and support should be provided to those who are ill or who are sufferer for the illness of parents or any other family members.

Further analytic studies with representative samples should be conducted which will include students with acceptable level of performance (students who pass regularly and if failure, not more than once during whole MBBS course) as well as students whose performance below acceptable level (defaulters and dropouts). This type of study will help to determine the reasons of defaulters and dropouts. So the appropriate strategy can be adopted to avoid dropouts and defaulters.
\end{abstract}

'Assistant Professor (CC), Dermatology \& Venereology, OSD,

DGHS, Mohakhali, Dhaka

${ }^{2}$ Associate Professor, Surgery, Center for Medical Education, Dhaka

${ }^{3}$ Professor, (Curriculum Development \& Evaluation), Center for Medical Education, Dhaka

${ }^{4}$ Junior consultant (Ped), MD (Phase B student), Pediatric

Hematology and oncology, BSMMU, Dhaka

${ }^{5}$ Research Associate, Center for Medical Education, Dhaka

${ }^{6}$ Lecturer, Center for Medical Education, Dhaka

${ }^{7}$ Assistant Professor, Gynecology \& Obstetrics, Mymensingh Medical College.

${ }^{8}$ Dental Surgeon

${ }^{9}$ Assistant Professor, Ophthalmology, OSD, DGHS, Dhaka.

${ }^{10}$ Junior Consultant, Orthopedic Surgery, Singair, Manikgang.

"Professor, Orthopedic Surgery, Barisal Medical College, Barisal

Address of correspondence: Dr. Md. Abdal Miah, MBBS, DDV, MD, MMEd, Assistant Professor (CC), Dermatology \& Venereology , OSD, DGHS, Mohakhali, Dhaka. Cell: 01711125263
Key Words: Reasons, dropout, defaulter, Medical students, Bangladesh

\section{Introduction}

Admission into medical colleges in Bangladesh is very tough and competitive one. It is necessary to have very high academic performance in SSC (O level) and HSC (A level) and to have very good performance in highly competitive nationwide admission test to get admission in a medical college in Bangladesh.

Appropriate selection of medical students is a fundamental prerequisite if medical schools are to produce competent and caring doctors ${ }^{1}$.

After a long process of admission, to become doctor, successful completion of the course in due time is essential and it is the desire for the student, family and also the nation. But the problem is that there are dropouts and repeated

Bangladesh Journal of Medical Education 2011;2(2):1-6. (C) 2011 Miah et al., publisher and licensee Association of Medical Education. This is an Open Access article which permits unrestricted non-commercial use, provided the original work is properly cited. 
failures (defaulters) in different professional examinations.

The magnitude of the problem in our country is not known due to unavailability of documentation. It is not known who are affected more and why are they affected. There are no such studies conducted in our country to measure the problem magnitude as well as the underlying causes of the problems.

So, it was intended to conduct a study on dropouts and defaulters of undergraduate medical students to describe the reasons of the dropouts and defaulters, and possible suggestions to avoid the occurrences of dropouts and defaulters of medical students in Bangladesh.

\section{Methods}

A descriptive cross sectional study was undertaken over a period of One year (July 2011 to June 2012) in 3 government\& 4 non-government medical colleges of Bangladesh. Dropouts and defaulters, who could be contacted and who were willing to participate in the study, were included in the study. Pretested instrumentwas used to collect data following convenience sampling method. Data was collected by in depth interview by the researcher himself. From the findings compilation sheet was prepared. Qualitative analysis was done by coding and recoding of the statements of the respondents and findings to put into different theme in relation to content and narrative summary. Informed consent was taken from each respondent. No identity of the respondents was disclosed to maintain strict privacy and confidentiality.

\section{Results}

Among the total 59 respondents, 48 respondents were defaulters and 11 respondents were dropped out from the course. Causes of dropouts and defaulters as well as suggestions for avoidance of dropouts and defaulters were explored.

\section{Causes of dropout and defaulters Socioeconomic and familial factors}

Poverty

"If my teacher could deeply understand that I am not disregarding her, rather I am bound to do something to earn to continue my studentship, then the teacher probably could do justice to me and my career could be better, poverty is worse than any other enemy."

Death of parent(s)

"My parents were murdered. How pathetic, how helpless I was! There was none to support me. There was none to say baba, how are you? In such a situation I could not attend classes regularly, could not appear examinations regularly and I was failing. In such a situation, teachers should be more friendly and should behave like parents, that could help me a lot."

Illness of Parent(s)

"Mymother was a patient of Ca breast, kidney cyst and myocardial ischemia. My father already expired in 2009. In such a situation I had to take care of my mother and had to take her to India on several occasions. Under this circumstance, I completed all cards but except head-neck card. For this, all percentages were cancelled and I was not allowed to sit for the $1^{\text {st }}$ professional examination another painful event added to my life. But if I had been shown a little bit of sympathy under this genuine ground and if I could sit for the examination and pass, it could help me to overcome many other academic and nonacademic sufferings. Please be kind to the genuine sufferers."

\section{Personal factors}

Illness

"I was sick with enteric fever, UTI \& hydronephrosis. Who will look after me? My parents were in KSA. So, I had to go to KSA for treatment and get rid of loneliness. But it took a lot of time. So, many percentage gap and defaulter. Here I had no personal fault. It was unavoidable for me. If tutorial teachers were more sympathetic to cover up the gap and percentages, I could succeed. I needed a little bit of sympathy and support, because my health problems were genuine. Be kind to the real suffer" Her eyes were full of tears- when talking with me.

Insincerity and irregularity

"I can't explain why? but I was insincere and irregular from the beginning. So, the result was failure. My realization is that, be regular from the beginning, be successful."

Failure to adjust with new environment

"I can't adjust with new environment. Everything is new: new person, new place, new study subjects, new system of examination, No old friends, relatives and parents. One should study in his or her own town or city."

Inability to face viva

"I feel very nervous to face viva. Attitude of the examiner seems to me tough and threatening. Please be kind and helpful to the examinee."

Inability to understand the subject "It is very tough to understand the medical subjects, particularly Anatomy. It is like brick to eat, so hard and tasteless. Oh teachers, be helpful to weaker students."

Difficulty in staying away from home

"I feel home sick very much. My body here but mind in own home as if it is a jail. Only cordial friends and helpful teachers can help me to get relief."

Marriage and pregnancy

"I got married in 1st year. After few months I conceived, so I had to face enormous problems, irregularity in class and examination. I could avoid all these problems if I could avoid marriage and pregnancy during student life." 
Lack of liking and interest for medical education

"My choice was to study engineering but was pushed by my parents to become a doctor. So I had lack of interest and confidence. Parents, please give priority to students' own choice to avoid such problem."

"I have no interest for medical education but was pushed by parents to private medical college. One should not study in medical if not get chance in Government Medical College."

Love affairs

"I fell in love, which caused lack of concentration for studies and consequently had bad result. One should not fall in love during student life."

\section{Institutional factors}

\section{Teacher factors}

"I was regular and sincere but percentage sheet was lost by teacher, so not sent up. Alas! Fault of one (teacher) but punishment to other (student)! There should be rule to punish such irresponsible teachers?"

"Percentage sheet was lost by the junior teacher, but I became a sufferer? There should be proper maintenance of records particularly percentage sheet at the student level, teacher level and office level".

Partiality

"Very pathetic, when I see some are passing due to jack (parents' doctor or political connection) and I am not, though similar or better student. Jack must be strictly avoided".

Political interference

"Politics and corruption creating difference among students, some are passing and some are not passing with similar background. Students should not involve in any activity other than study. I feel depressed when I see I am not passing but my friend is passing as he has political connection."

Hostel problem

"No hostel, no group discussion, no reading partner: Just like refugee! How can I pass!"

Poor institutional set up and quality causing unavoidable migration to new medical college causing delay (time loss) and maladjustment with new environment

"We did not get admitted to medical college for migration. We were bound to do it. But new institution and environment could not accept us well. Step mother like attitude even by the yearmates, what a tragedy without fault? Only cordiality and helpful attitude of friends and teachers can save us."

Administrative rigidity

\section{Curriculum factors}

Curriculum

"Vast and overloaded curriculum. Endless, I feel I am sinking in it. Curriculum should be appropriate and interesting."
Lack of coordination between class time and examination schedule

Difficult examination system

"I fear viva. Written is ten times easier than one time viva. Maintain frequent contact and good relation with teachers to overcome it."

\section{Findings regarding suggestions to prevent dropout and defaulters}

Most of the qualitative questions were open ended. It was found that majority of the respondents mentioned about the suggestions to reduce or avoid dropout and defaulter in the medical course. The suggestions were:

1. One most important suggestion by the respondents was to maintain regularity and sincerity in all types of classes including tutorials, practical and examinations strictly.

2. Another important suggestion was that there should be an enabling environment where the junior and senior teachers including examiners are friendly, interactive and have special sympathy towards students. That type of enabling environment may reduce the gaps of students who missed classes, tutorials or practical classes and eventually these students will be engaged in study with the help of teachers and would be able to meet with mainstream.

3. Parents should consider the student's interest and ability for admission into medical colleges.

4. Strategies of study like reading partnership study may reduce fear of examination. In this regard, teachers and senior students can play an important role to encourage the students.

5. Proper hostel arrangement with proper food, accommodation and recreation facilities sometimes make reluctant student active to meet the mainstream and continue the study. So these systems should be improved.

6. There should be well organized set up of counseling and arrangement of make-up classes for backward students.

7. Personal affairs sometimes hinder regular study of the students like love affairs, marriage, and pregnancy. So these types of involvement should be avoided during student life.

8. The medical curriculum should be appropriate, more interesting and practical oriented and examination system should be easier.

9. Permission to start new medical college should be given only after complete fulfillment of all criteria and migration should not cause any time loss to the student.

10. Institution should be free from student and teacher politics, corruption and favoritism. 
11. For foreigner students there should be special arrangement so that they can stay together in hostel for accommodation, special food and recreation for them.

12. Special sympathy and helping attitude should be for those who are themselves ill or their parents or family members are ill.

\section{Discussion}

In a country like Bangladesh, where medical facilities are not adequate and doctor-patient ratio still poor, the maximum output of qualified doctors (MBBS) in minimum time is a purposeful strategy. Contrary to the expectation of the students themselves, families and the nation, there are occurrences of defaulters and dropouts. So, the country is deprived of getting the expected number of MBBS doctors in expected time.

In a study in India, showed that about $5.4 \%$ seats were wasted each yearand the loss to the government, for each seat is approximately Rs one lac annually ${ }^{2}$. Each medical seat is highly valuable in economic terms as well as wasted manpower and time ${ }^{3}$

Socio-economic and family background, personal, institutional and curriculum characteristics and their influences on defaulters and dropouts:

Medical education is an expensive study. So, per month family income is expected to be an important factor. One of our respondents was saying "poverty is more dangerous than any other enemy". Khan et $\mathrm{al}^{4}$ found that $18.2 \%$ of medical students had financial problem and financial problem was identified as a factor for dropout by Smith \& Naylor ${ }^{5}$.

Illness or loss of guardian or family member was pointed out as contributory factor by some of the defaulters and dropouts.

Political involvement was considered as an influential factor to be a defaulter and dropout by a portion of respondents. Some were saying "One should not involve in politics during student life".

A portion of defaulters and many of dropouts were involved in love affairs. Involvement in love affairs and consequently marriage and pregnancy were thought to affect significantly class attendance and overall performance by them. Many were saying "one should not be involved in love", "One should avoid marriage and pregnancy during student life".

Personal liking and interest to be a doctor is very important to continue and complete the MBBS course duly. A good number of defaulters and many of the dropouts was admitted in medical school without their own motivation to be a doctor. This was also reflected in their statements: "I wanted to be engineer but was pushed by my parents to become a doctor." Similar statements were made by some other respondents as well. Khan et al showed that $17.6 \%$ had no interest for studying MBBS course.
Many of the students were saying "It is very tough to understand the medical subjects, particularly anatomy. One was stating "It is like brick to eat, so hard and tasteless". "I could not understand the subject, just trying to memorize. But it was really impossible" said by some others. All these indicate that to do anything, personal ability is very important. This is more correct for medical education. So they suggested that parents should give utmost importance to the interest and ability of their children before admission into medical colleges to avoid defaulters and dropouts.

Personal ill health and RTA was interfering with academic performances including failure to sit in the examination in due time as noted by some of the defaulters and dropouts. Personal and family health factor can influence the academic performance was also found in a study by Stettoet $\mathrm{al}^{6}$. Our respondents' suggestion was that special sympathy and helping attitude could improve their performance.

Some were saying: "I cannot adjust with new environment. Everything is new: new person, new place, new study subjects, new examination system. One should study in his or her own town or city". One was saying "I feel homesick very much. My body here but mind in own home, as if it is a jail".Home sickness was one of the causes to failure to concentrate in academic activities as revealed from above statements.

Many defaulters and dropouts could not adjust with the nature of the course and the teaching methods so, they were unable to concentrate and conceive the subject matter resulting in loss of interest and eventually leading to repeated failure and some were ultimately ended as dropped out.

Ward et $\mathrm{al}^{7}$ found that students having a shy and timid personality have an increased chance of dropping out of medical school relative to their counterpart. One of the respondents was telling "I feel shy to face viva and cannot speak in front of the examiners" indicate that this factor was also evident as a cause of repeated failure and dropping in this study as stated by some of our respondents.

Many of our respondents' claimed the institutional environment regarding infrastructure, resource availability, administrative support, political interference and accommodation facilities were not encouraging to overcome their difficulties to avoid these mishaps. One study by Khan et $\mathrm{l}^{4}$ found that students were showing their concern about lack of recreation facilities in hostel and Arulampalam et $\mathrm{al}^{8}$ found that students who lived on campus had lower rates of dropout. The suggestions from our respondents were, the policy makers should be aware regarding the standard set up before giving permission for a new medical institute and there should be adequate number of seats with good quality food and recreation facilities in all, that can help to avoid loneliness and help to develop reading partnership and group discussion to avoid these unwanted performances. 
In depth analysis revealed a group of respondents who were insincere and irregular from the beginning without any acceptable reason, which had made a long gap with the mainstream and was almost unrecoverable resulting in repeated failure eventually leading to dropout. So, their suggestion was to be sincere and regular from the very beginning to avoid all unwanted consequences. Early intervention is important to retaining students in a pipeline that leads to a health care career. Another important conclusion is that much more needs to be done to help students find mentors with whom they can develop relationship and to give them opportunity to work in health care settings'.

Non-friendly and threatening attitude of the senior teachers and examiners particularly with the poor performers was an important factor and irresponsibility in keeping records of students file by some of the teachers was claimed as important cause for their poor outcome. In a study it was found, $52.8 \%$ of students claimed that teachers do not bother to gain students attention and $47.2 \%$ students had examination phobia. Teachers should be nonthreateningand cooperative, give special attention to the students showing poor performance and help students to reduce examination phobia ${ }^{4}$. Similar suggestions came from the respondents of the present study. Facilities for counseling for poor performers are very important. But there was no organized set up or department in any of medical college under study. They felt that it would be helpful to overcome their difficulties if a set up facilities for counseling and remedial actions. A recent study found that a mandatory academic support program for at risk students seemed to result in improved retention rates at a medical school compared with historical controls ${ }^{10}$.

\section{Curriculum factors (Table 22)}

It was stated by the respondents that curriculum content was overloaded. Khan et al ${ }^{4}$ found that more than fifty percent of the students think that the curriculum content was overloaded. There is strong association between curriculum status and dropout ${ }^{6}$ and long courses, too much theory at the expense of practical training, are blamed for high dropout rate in Austria ${ }^{11}$. Professional examination can be taken more frequently to reduce the subject load in a single examination as suggested by some of the students. Many were claiming the non- coordination between class schedule and item examination and too much item examination was the cause of failure to cope with the curriculum.

Respondents of the present study suggested that curriculum should be appropriate in regard of its contents, more interesting and practical oriented and examination system should be easier. There should not be any lack of coordination between class schedule and examination schedule. A series of suggestions came from Hussainet $\mathrm{al}^{12}$, smaller group and interactive sessions; more number of clinical, practicaland problem oriented sessions taken by senior and experienced teachers. Although Strayhorn ${ }^{13}$ found no effect of curriculum type on dropout but it was found that dropout rate is higher $(23 \%)$ with traditional curriculum than that of problem based curriculum $(10 \%)^{14}$. Khan et al ${ }^{4}$ suggested that curriculum should be community oriented; core and additional contents should be identified and examinations should be carried out accordingly.

Choudhry et $\mathrm{al}^{2}$ suggested remedies, to maintain better standards of medical education, curriculum planners have to provide more teaching staff to enable extra small group teaching. Students of categories II (students nominated by government and defense and category III (students from schedule caste and schedule tribe students) should be given language and orientation courses before they embark on the difficult medical syllabi ${ }^{2}$.

\section{Conclusion and Recommendations}

The important reasons for dropout and defaulters as suggested by the respondents were; lack of interest and capability of the students, non-friendly and non-cooperative attitude of the teachers, content overloaded curriculum, lack of counseling facilities and illness of the students and or family members.

To prevent the dropout and defaulters, students should be serious and sincere from the beginning, teachers and examiners should be cooperative, responsible and rational, and curriculum should be appropriate and interesting, there should be counseling facilitiesand students' interest and ability should be given proper and utmost importance in case of medical admission.

Further analytic study with representative samples should be conducted which will include students with acceptable level of performance (students who pass regularly and if failure, not more than once during whole MBBS course) as well as students whose performance below acceptable level (defaulters and dropouts). This type of study will help to determine the reasons of defaulters and dropouts. So the appropriate strategy can be adopted to avoid dropouts and defaulters.

\section{Reference}

1. Rolfe IE, Pearson S, Powis DA, \& Smith AJ, Time for a review of admission to medical school?, Lancet, vol.346, pp. 1329-1333

2. Choudhry R, Garg K, Gaur U \&Anand C 1997, Academic performance of various categories of students admitted to lady Hardinge Medical college, New Delhi, J India Med Assoc, vol. 95, no.2, pp. 45-47

3. O' Neill LD, Wallstedt B, Eika B \&Hartvigsen J 2011, Factors associated with dropout in medical education: a literature review, Med Educ, vol. 45, pp. 440-54.

4. Khan TF, Chowdhury FP, Asaduzzaman AKM \&Mashreky SR 2006, Students evaluation and needs about the present MBBS curriculum, JAFMC Bangladesh, vol.2, no.1, pp.20-24. 
5. Smith JP \& Naylor RA 2001, Dropping out of University: a statistical analysis of the probability of withdrawal for UK University students, JR Statist Soc A, vol. 164,pp. 389-405

6. Stetto JE, Gackstetter GD, Cruess DF \& Hooper TI 2004, Variables associated with Attrition from uniformed services University of the Health Sciences Medical School, Milit Med, vol. 169, no. 2, pp. 102-7

7. Ward AM, Kamien M\& Lopez DG 2004, Medical career choice and practice location: early factors predicting course completion, career choice and practice location, Med Educ, vol.38, no.3, pp.239-48.

8. Arulampalam W, Naylor R \& Smith J 2007, Dropping out of medical school in the UK: explaining the changes over 10 years, Med Educ, vol. 41, pp. 385-94.

9. Thurmond VB \&Cregler LL 1999, Why students drop out of the pipeline to health professions careers: A follow-up of gifted minority high school students, Acad Med, vol.74, no.4, pp.448-451.

10. Winston KA, Van Der Vleuten CPM \& Scherpbier AJJA
2010, An investigation into the design and effectiveness of a mandatory cognitive skills programme for at-risk medical students, Med Tech, vol.32, no.3, pp.236-43.

11. Glass N 1999, Austrian tackle medical school dropout, The Lancet, vol.353, p. 1424.

12. Hussain MM, Talukder HK, Moazzem N, Rashid A, Hanif A\&Nargis T 2002, Evaluation of existing curriculum (2002) of undergraduate medical education in Bangladesh, MMJ. vol.20, no. 2, pp.226-32.

13. Strayhorn G 1999, Participation in a pre-medical summer program for under-represented minority students as a predictor of academic performance in the first three years of medical school: two studies, Acad Med, vol.74, no,4, pp.435-47.

14. Iputo JE \&Kwizera E 2005, Problem-based learning improves the academic performance of medical students in South Africa, Med Educ, vol.39, no.4, pp.388-93. 